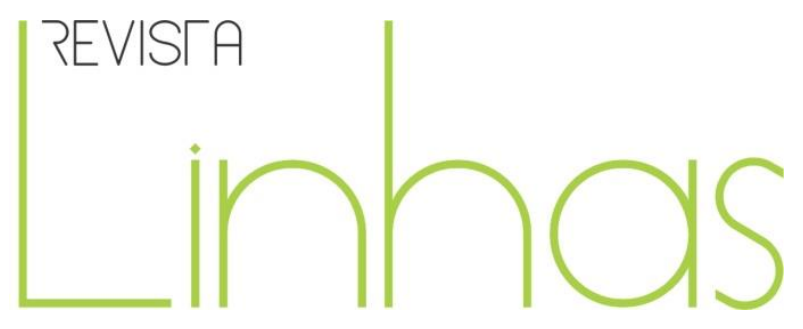

\title{
Percepção dos docentes de Atendimento Educacional Especializado acerca da valorização do seu trabalho
}

\section{Resumo}

O objetivo deste artigo foi conhecer a opinião dos professores de Atendimento Educacional Especializado acerca de como estes enxergam a valorização de seu trabalho pelos diversos indivíduos que permeiam direta ou indiretamente o ambiente escolar. Os dados foram coletados através de questionário com perguntas fechadas, aplicado a 36 docentes de Atendimento Educacional Especializado dos municípios da região do Piemonte da Diamantina, estado da Bahia. De forma resumida, os achados indicam que os docentes de AEE participantes do estudo acreditam que quem mais valoriza o seu trabalho são os seus próprios alunos, seguidos dos familiares desses alunos, dos outros profissionais que, por ventura trabalham na sala de recursos, e o Coordenador(a) pedagógico(a) da escola onde ocorre o atendimento. Entretanto, os mesmos professores creem que os outros alunos que frequentam as salas de aula regular e os seus respectivos professores, além do(a) Diretor(a) da escola, da Secretário(a) de educação e de outros funcionários da escola apenas valorizam em parte o seu trabalho.

Palavras-chave: Atendimento Educacional Especializado; Educação Especial; valorização docente.
Osni Oliveira Noberto da Silva

Universidade do Estado da Bahia -

UNEB - Salvador/BA - Brasil

osni_edfisica@yahoo.com.br

Theresinha Guimarães Miranda

Universidade Federal da Bahia -

UFBA - Salvador/BA - Brasil

tmiranda@ufba.br

Miguel Angel Garcia Bordas

Universidade Federal da Bahia -

UFBA - Salvador/BA - Brasil magbordas@gmail.com

\section{Para citar este artigo:}

SILVA, Osni Oliveira Noberto da; MIRANDA, Theresinha Guimarães; BORDAS, Miguel Angel Garcia. Percepção dos docentes de Atendimento Educacional Especializado acerca da valorização do seu trabalho.

Revista Linhas. Florianópolis, v. 22, n. 49, p. 402-417, maio/ago. 2021. 


\title{
Perception of Specialized Educational Service teachers about the valuation of their work
}

\begin{abstract}
The aim of this paper was to know the opinion of teachers of Specialized Educational Care about how they see the valuation of work by the various individuals that directly or indirectly permeate the school environment. Data were collected through a questionnaire with closed questions applied to 36 teachers of Specialized Educational Assistance in the municipalities of the Piedmont of Diamantina region, state of Bahia. Briefly, the findings indicate that the ESA teachers participating in the study believe that the ones who value their work the most are their own students, followed by their students' families, the other professionals who may work in the resource room and the Coordinator. pedagogical of the school where the service occurs. However, the same teachers believe that other students attending regular classrooms and their respective teachers, in addition to the school principal, the secretary of education and other school staff, only partially value your job.
\end{abstract}

Keywords: Specialized Educational Service; Special education; teacher appreciation. 


\section{Introdução}

É inegável a importância que os professores têm em uma sociedade. Países com maior índice de desenvolvimento humano têm em comum a valorização da profissão docente em seus diversos aspectos: financeiro, formação, estrutura física, entre outros (BASTOS, 2016).

Entretanto, muito por conta das teorias neoliberais que começaram a ser introduzidas nas políticas públicas das nações, principalmente aquelas nações em desenvolvimento ou pobres, a figura do professor e tudo que ela representa começa a ser atacada, haja vista que a educação passa a ser encarada como produto e não como direito; os alunos como clientes e os professores como operários em uma fábrica de produção em massa.

Segundo Oliveira e Maúes (2012) “os professores se tornaram alvo das políticas de inspiração neoliberal, mediante surgimento de diretrizes, programas e ações orientadas para a regulação e o controle profissional por meio de aferição e remuneração por desempenho" (p. 67). Assim, com as políticas neoliberais focadas na eficiência e na redução do papel do Estado, os professores começaram a sofrer uma série de ataques em seus direitos, além de terem sido culpabilizados pelo fracasso das políticas educacionais, “produzindo, segundo essa ótica, a perpetuação das desigualdades, do baixo rendimento dos alunos e a repetência e o abandono da escola" (FREITAS, 2012, p. 91).

Desse modo, os problemas de falta de valorização dos professores que ocorrem em outras nações também existem de forma intensa no Brasil. Ainda que resguardando poucas diferenças, as consequências que as políticas de cunho neoliberal geram, seguem um padrão que inclui diminuição dos salários, formação precária, carga horária excessiva e, atualmente, até desrespeito por parte dos governantes (BOUKOU, 2017; GALGÓCZI; GLASSNER, 2008; TOH, 2017; TOURIGNY, 2017).

Além disso, a desvalorização da profissão docente, aliada às situações estressantes do dia a dia, como violência escolar, baixos salários entre outros, levam os professores a desenvolverem uma série de acometimentos da saúde, como explicado por Caye et al. (2014): 
Os professores pertencem a uma classe de profissionais especialmente expostos aos riscos psicossociais, por estarem defrontando-se com fatores desencadeantes de estresse próprios da organização acadêmica e escolar e com situações nas quais se desequilibram as expectativas individuais do profissional e a realidade do trabalho diário. (CAYE, 2014, p. 986-987)

A relevância desse assunto é tamanha que a própria Constituição Brasileira de 1988, nos incisos V e VIII do artigo 206, reserva espaço específico para tratar sobre a valorização não só dos professores, mas de todos os profissionais da educação. Segundo o documento:

V- valorização dos profissionais da educação escolar, garantidos, na forma da lei, planos de carreira, com ingresso exclusivamente por concurso público de provas e títulos, aos das redes públicas; [...]

VIII - piso salarial profissional nacional para os profissionais da educação escolar pública, nos termos de lei federal. (BRASIL, 1988, art. 206)

A valorização dos profissionais de educação inserida posteriormente na Lei Federal $n^{\circ}$ 9394/96, também conhecida como Lei de Diretrizes e Bases da Educação (LDB), especialmente no artigo 67, apresenta os elementos que precisam ser levados em consideração:

Os sistemas de ensino promoverão a valorização dos profissionais da educação, assegurando-lhes, inclusive nos termos dos estatutos e dos planos de carreira do magistério público:

I - ingresso exclusivamente por concurso público de provas e títulos;

II - aperfeiçoamento profissional continuado, inclusive com licenciamento periódico remunerado para esse fim;

III - piso salarial profissional;

IV - progressão funcional baseada na titulação ou habilitação, e na avaliação do desempenho;

$\checkmark$ - período reservado a estudos, planejamento e avaliação, incluído na carga de trabalho;

VI - condições adequadas de trabalho. (BRASIL, 1996, art. 67)

De acordo com Oliveira e Pires (2014), mesmo que a legislação trate sobre a questão da valorização docente, muitos governos nacionais, o do Brasil inclusive, começaram de forma gradativa a diminuir sua responsabilidade no financiamento e 
manutenção da qualidade da Educação pública, que afeta invariavelmente e diretamente as condições de trabalho dos professores.

De acordo com Tostes (2018), a sobrecarga de trabalho a que o professor é submetido acaba por culpabilizá-lo diretamente pelo fracasso escolar. E, ainda, segundo o autor:

Enquanto a valorização dos professores diminui, cresce a cobrança para que a escola cumpra funções antes legadas a outras instituições sociais, como a família. O professor vem assumindo uma gama de funções, além daquelas tradicionalmente conferidas à especificidade de seu trabalho, sendo, ao mesmo tempo, desqualificado e sobrecarregado. Estimular o potencial de aprendizagem dos alunos, ensiná-los a conviver em sociedade, cobrir as lacunas da instituição escolar, garantir a articulação entre escola e comunidade, e buscar, por conta própria, sua requalificação profissional, são algumas das tarefas que ilustram sua atual condição. (TOSTES, 2018, p. 89)

Por conta disso, os jovens egressos do ensino médio cada vez menos procuram entrar em cursos de Licenciatura, haja vista o cenário brasileiro de desvalorização do trabalho do professor, como explicado por Silva (2017):

Outrossim, a profissão docente se vê alijada de prestigio social, o contrário das demais profissões liberais, como médicos, advogados, arquitetos, entre outros. Isso faz com que a profissão docente se enquadre no grupo das semiprofissões, pois compartilha características tanto da profissionalização quanto da proletarização. (SILVA, 2017, p. 40)

De acordo com Freitas (2012, p. 91), as políticas neoliberais alteraram substancialmente a figura do professor enquanto profissão e trouxeram péssimas consequências a toda a educação, como explicado pelo mesmo autor:

a crítica às reformas [...] aponta que, em consonância com o modelo de ajuste neoliberal, prevaleceram, no período, políticas centradas na gestão, eficiência, gerência e de redução do papel do Estado, à revelia dos professores, atribuindo seu fracasso ao baixo protagonismo dos professores em sua implementação, produzindo, segundo essa ótica, a perpetuação das desigualdades, do baixo rendimento dos alunos e a repetência e o abandono da escola. (FREITAS, 2012, p. 91) 
Assim, as discussões até aqui apresentadas demonstram a relevância do tema em questão. Por conta disso, o objetivo deste artigo foi conhecer a opinião dos professores de Atendimento Educacional Especializado (AEE) acerca de como observam a valorização de seu trabalho pelos diversos indivíduos que permeiam direta ou indiretamente o ambiente escolar.

Para fins de conceituação, o Atendimento Educacional Especializado é definido, segundo o artigo $2^{\mathrm{a}}$, parágrafo $1^{\circ}$ do Decreto 7.611/2011, como:

[...] o conjunto de atividades, recursos de acessibilidade e pedagógicos organizados institucional e continuamente, prestado das seguintes formas:

I- complementar à formação dos estudantes com deficiência, transtornos globais do desenvolvimento, como apoio permanente e limitado no tempo e na frequência dos estudantes às salas de recursos multifuncionais; ou II - suplementar à formação de estudantes com altas habilidades ou superdotação. (BRASIL, 2011, art. 2)

O AEE é previsto em escolas comuns e os alunos público-alvo têm seu atendimento no contra turno da sala de aula regular. Assim, o AEE não é um substituto ao trabalho realizado nas salas de aula regulares, já que ele precisa conviver harmonicamente com as aulas do ensino regular para garantir o desenvolvimento educacional dos alunos (BRASIL, 2011).

É importante esclarecer que os dados apresentados neste texto são parte integrante de estudo realizado em nível de Doutoramento, desenvolvido no Grupo de Estudos sobre Educação Inclusiva e Necessidades Educacionais Especiais (GEINE), na Faculdade de Educação da Universidade Federal da Bahia (FACED/UFBA), e financiado através de bolsa ofertada pelo Programa de Apoio à Capacitação de Docentes (PAC-DT) da Universidade do Estado da Bahia. 
Os dados desta pesquisa, responsáveis pelo cumprimento do objetivo proposto, foram coletados por meio de um questionário produzido especificamente com perguntas fechadas e de múltipla escolha, sendo assim uma ferramenta importante para que se possa captar as diferentes opiniões, interesses, sentimentos e crenças dos sujeitos entrevistados (GIL, 2010). As perguntas visaram contemplar os elementos referentes à categoria da valorização do trabalho docente pelos outros atores que direta ou indiretamente influenciam em seu trabalho na escola.

Os sujeitos participantes obedeceram aos seguintes critérios de inclusão: professores, de ambos os sexos, que no ano de 2017 tenham atuado há pelo menos um ano com Atendimento Educacional Especializado em salas de recursos multifuncionais de escolas municipais, urbanas e rurais, dos nove municípios ${ }^{1}$ que compõem a região do estado da Bahia, conhecida como Piemonte da Diamantina. Desse modo, após o levantamento de informações junto às prefeituras dos respectivos municípios, foi possível observar que 45 docentes se encaixavam dentro desse critério. O questionário, então, foi aplicado a 36 sujeitos que aceitaram participar desse estudo, sendo 35 mulheres.

A coleta de dados ocorreu entre os dias 26 de março a 04 de dezembro de 2018. 0 preenchimento do questionário foi realizado de forma presencial, de maneira que os horários das coletas foram previamente ajustados com os sujeitos. Os participantes foram provocados a expor suas impressões acerca de como seu trabalho é visto pelos diversos atores do ambiente escolar, divididos em nove itens, de modo que foi solicitado que classificassem cada um deles em "Muito Valorizado", "Valorizado em Parte", “Desvalorizado" e "Indiferente".

Em atenção às normas éticas de pesquisa com seres humanos, além de legitimar a participação voluntária dos sujeitos, foi lhes apresentado um documento chamado de Termo de Consentimento Livre e Esclarecido (TCLE), que garante o uso dos dados coletados para fins estritamente acadêmicos e assim, manter a identidade dos professores preservada. Além disso, o estudo foi construído respeitando a Resolução nº

\footnotetext{
1 Os municípios são: Caém, Jacobina, Miguel Calmon, Mirangaba, Ourolândia, Saúde, Serrolândia,
} Umburanas e Várzea Nova. 
466/2012 que trata sobre a pesquisa com seres humanos e a Resolução 510/2016 que foca especificamente em normas para pesquisas na área de Ciências Humanas e Sociais.

\section{Apresentação e análise dos dados}

Os dados coletados neste estudo dizem respeito à valorização do trabalho dos professores de AEE perante os diversos atores que eles convivem profissionalmente na escola. Por conta disso, as respostas foram agrupadas e apresentadas em forma de porcentagem na tabela 1. As respostas foram divididas em quatro categorias: “Indiferente”, “Desvalorizado”, “Valorizado em parte” e “Muito valorizado”.

Tabela 1 - Percepção docente sobre como seu trabalho de professor que atua com AEE é visto

\begin{tabular}{|l|c|c|c|c|}
\hline & $\begin{array}{c}\text { Muito } \\
\text { Valorizado }\end{array}$ & $\begin{array}{c}\text { Valorizado } \\
\text { em parte }\end{array}$ & Desvalorizado & $\begin{array}{c}\text { Indiferent } \\
\text { e }\end{array}$ \\
\hline Pelos alunos do AEE & $\mathbf{7 8 \%}$ & $\mathbf{1 9 \%}$ & $\mathbf{0 \%}$ & $\mathbf{3 \%}$ \\
\hline Pelos outros alunos da escola & $\mathbf{2 0 \%}$ & $\mathbf{5 8 \%}$ & $\mathbf{8 \%}$ & $\mathbf{1 4 \%}$ \\
\hline $\begin{array}{l}\text { Pelos familiares dos alunos do } \\
\text { AEE }\end{array}$ & $\mathbf{5 8 \%}$ & $\mathbf{3 6 \%}$ & $\mathbf{0 \%}$ & $\mathbf{6 \%}$ \\
\hline Outros profissionais na SRM & $\mathbf{4 9 \%}$ & $\mathbf{4 5 \%}$ & $\mathbf{3 \%}$ & $\mathbf{3 \%}$ \\
\hline Outros professores da escola & $\mathbf{2 5 \%}$ & $\mathbf{5 6 \%}$ & $\mathbf{8 \%}$ & $\mathbf{1 1 \%}$ \\
\hline Pela Direção da escola & $\mathbf{4 5 \%}$ & $\mathbf{4 7 \%}$ & $\mathbf{8 \%}$ & $\mathbf{0 \%}$ \\
\hline Secretário(a) de educação & $\mathbf{4 2 \%}$ & $\mathbf{5 0 \%}$ & $\mathbf{3 \%}$ & $\mathbf{5 \%}$ \\
\hline Coordenador(a) pedagógico(a) & $\mathbf{5 3 \%}$ & $\mathbf{3 9 \%}$ & $\mathbf{3 \%}$ & $\mathbf{5 \%}$ \\
\hline Outros funcionários da escola & $\mathbf{2 8 \%}$ & $\mathbf{6 4 \%}$ & $\mathbf{0} \%$ & $\mathbf{8 \%}$ \\
\hline
\end{tabular}

Fonte: Elaboração própria, 2019.

No que diz respeito à valorização do Atendimento Educacional Especializado por parte dos próprios alunos, $78 \%$ das docentes pesquisados acreditam que são "muito valorizados". 19\% disseram que se sentir "valorizados em parte" e 3\% acreditam que os alunos do AEE são “indiferentes”. Nenhum professor se sentiu “desvalorizado" por seus alunos de AEE. A partir dos dados apresentados é possível inferir que os docentes e discentes do AEE possuem uma ótima relação, o que é algo importante para o melhor aproveitamento e sucesso do atendimento.

De acordo com Abrão e Duarte (2017), a existência de uma relação de confiança e, consequentemente, valorização entre professor do Atendimento Educacional 
Especializado e seus alunos pode contribuir diretamente para o desenvolvimento educacional, social e afetivo. Para Mauch e Santana (2016), a relação entre professor e aluno também pode ser entendida como um processo formativo que pode influenciar diretamente no aprendizado. E, ainda, segundo os mesmos autores:

\begin{abstract}
Assim, cursos, seminários e outras ações de formação não são os únicos espaços formativos para os profissionais das escolas inclusivas. No trabalho de campo dessa pesquisa, nas visitas às escolas, foram recorrentes os depoimentos a respeito do quanto se aprende com a convivência cotidiana com os alunos e na busca de soluções para questões de ensino e aprendizagem. São muito comuns também falas que mencionam quanto foi preciso inovar e aprender para atender às características de determinado aluno e quanto a experiência com os alunos que são público-alvo da educação especial transformou os educadores em profissionais mais capazes e bem preparados a ensinar 0 conjunto dos alunos, com e sem deficiência. (MAUCH; SANTANA, 2016, p. 57)
\end{abstract}

No que diz respeito à valorização por parte dos alunos da sala de aula regular, $58 \%$ dos docentes de AEE afirmam que se sentem "valorizados em parte", 20\% se sentem "muito valorizados", 14\% dos docentes acreditam que os alunos são "indiferentes" e $8 \%$ se sentem “desvalorizados” pelos alunos da sala de aula regular. É possível observar que alguns docentes ainda percebem a importância do trabalho realizado no AEE.

No que diz respeito à valorização pelos pais dos alunos de $\mathrm{AEE}, 58 \%$ dos professores disseram se sentir "muito valorizados", 36\% acreditam que são "valorizados em parte" e 6\% dos docentes afirmaram que os familiares são "indiferentes" a esse tema. É possível inferir que existe um sentimento dos professores de AEE de valorização perante a maioria dos pais e mães dos alunos. Isso acaba influenciando diretamente no bom desenvolvimento do atendimento, pois é responsabilidade dos familiares garantir a frequência e a motivação dos alunos no AEE.

De acordo com Mauch e Santana (2016), analisando vários municípios brasileiros, observaram que o maior envolvimento dos pais e mães dos alunos com deficiência gera uma valorização maior no trabalho docente: 
Em vários municípios estudados, os coordenadores dos setores responsáveis pelas políticas de educação inclusiva afirmaram que as famílias dos alunos com deficiência, TEA, TGD e altas habilidades/superdotação estão mais participativas. Uma das razões apontadas em diferentes municípios é o maior conhecimento em relação aos direitos das pessoas com deficiência, especialmente a educação inclusiva. Além disso, as famílias têm sido mobilizadas pelas redes de ensino para questões concretas, como o direito ao AEE, a troca de informações sobre os alunos (outros atendimentos clínicos recebidos, características pessoais, discussão de estratégias para o atendimento escolar etc.), e também têm sido envolvidas em outros espaços de participação, como conselhos, elaboração do Projeto PolíticoPedagógico, avaliações etc. (MAUCH; SANTANA, 2016, p. 40)

Em relação aos outros profissionais que por ventura atuam na sala de recursos multifuncionais, 49\% dos professores de AEE consideram que são "muito valorizados", $45 \%$ acreditam que são "valorizados em parte", $3 \%$ se sentem "desvalorizados" e outros $3 \%$ acham que eles são "indiferentes". Os dados sugerem que a maioria valoriza os profissionais de AEE.

No que diz respeito à valorização por parte dos professores que atuam nas salas de aula regulares, 56\% dos docentes de AEE consideram que são "valorizados em parte", $25 \%$ acreditam que são "muito valorizados", $11 \%$ são "indiferentes" e apenas $8 \%$ sentem que seu trabalho é "desvalorizado". Sobre a valorização por parte do(a) diretor(a) da escola, 47\% dos professores de AEE se dizem "valorizados em parte", 45\% acham que são “muito valorizados" e $8 \%$ acham que são “desvalorizados” por esse profissional.

A respeito da valorização do(a) Secretário(a) de educação do município, metade dos professores de AEE (50\%) acham que são valorizados em parte, 42\% acreditam que são "muito valorizados", 5\% consideram que o(a) Secretário(a) é "indiferente" ao trabalho no AEE e 3\% acreditam que seu trabalho é “desvalorizado". No que tange à valorização do(a) Coordenador(a) pedagógico(a), 53\% dos docentes acham que são "muito valorizados", 39\% responderam que são "valorizados em parte", 5\% acreditam que são “indiferentes” e $3 \%$ se sentem “desvalorizados” por este profissional. É possível observar que os professores de AEE apresentam uma percepção de que são valorizados pelos gestores da secretaria municipal de educação, da escola e também pela coordenação pedagógica. 
Por último, os dados indicam que 64\% dos docentes de AEE acham que seu trabalho é "valorizado em parte" pelos outros funcionários que trabalham nos diversos setores da escola, como limpeza, portaria e merenda. Já $28 \%$ acham que são "muito valorizados" e somente $8 \%$ acreditam que são tratados de maneira "indiferente" por esses profissionais. Foi possível observar que, de acordo com a percepção dos docentes de AEE, o seu trabalho é valorizado pela maioria dos outros atores da escola, o que indica um resultado positivo.

De acordo com Silveira (2012), ainda que exista preocupação acerca da valorização do trabalho docente na Educação Especial, inclusive com garantias na legislação vigente, ainda há um longo caminho a ser trilhado para que essa valorização seja ampliada diante de toda a sociedade.

Miranda (2016), em uma pesquisa com oito docentes de AEE do sexo feminino de oito escolas municipais de Salvador/BA, relatou que as professoras disseram não se sentirem valorizadas pelos professores da sala de aula regular, sendo que alguns até desconheciam o objetivo e a importância do AEE.

Alguns estudos como o de Oliveira (2015) evidenciaram que as docentes de AEE não se sentem reconhecidas e valorizados por seu trabalho. Algumas professoras inclusive disseram ter sido chamadas de "preguiçosas" por colegas docentes das salas de aula regular, porque os atendimentos ocorrem de forma individual e com hora marcada. Situação bem diferente das salas de aula comum, sempre lotadas. Em outro relato, as professoras de AEE frequentemente eram solicitadas para dar aula de reforço a alunos que não eram seu público-alvo ou ainda a substituírem os colegas da sala comum que faltavam.

Segundo Miranda (2016), essa falta de valorização tem como uma das causas a não existência de momentos de formação e integração entre os professores de AEE e da sala de aula comum, o que contribui para que ocorra um desrespeito pelo trabalho desenvolvido e pela colaboração mútua. Concordando com esse argumento, Venturini e Senna (2014) afirmam que a desarticulação entre esses dois profissionais advém da própria falta de conhecimento dos professores da sala de aula regular em lidar com alunos com deficiência e/ou necessidades educacionais especiais. 
Assim, diversos estudos, como os de Mauch e Santana (2016) afirma que muitos ganhos educacionais ocorrem quando existe valorização do trabalho do professor de Atendimento Educacional Especializado pelos gestores e pelos docentes da sala de aula comum. E, ainda, de acordo com os mesmos autores:

Nas escolas em que o trabalho está mais consolidado, é inegável o papel central dos professores de AEE, que atuam de forma articulada com a equipe gestora e constituem-se, muitas vezes, como parte da equipe gestora para as questões de educação inclusiva - quadro que configura uma coordenação ampliada. Esse arranjo recorrente explicita estratégias e formas de organização que, sem sombra de dúvida, valorizam o trabalho dos profissionais e fortalecem a articulação entre as equipes. No entanto, é necessário um trabalho intenso, principalmente por parte dos gestores das secretarias, no que diz respeito à definição de papéis da equipe de gestão escolar, com o objetivo de não concentrar no professor de AEE a responsabilidade de gestão da educação inclusiva nas escolas. (MAUCH; SANTANA, 2016, p. 76)

De acordo com Menezes (2016), é importante que tanto a comunidade escolar quanto a sociedade em geral sejam convidadas a conhecer o trabalho desenvolvido pelo Atendimento Educacional Especializado, para assim descobrirem a sua importância para o desenvolvimento educacional, social e afetivo de seus alunos, de maneira que todos possam valorizar, cuidar e lutar pela melhora constante das condições do atendimento. Aautora completa:

É importante que todo cidadão conheça o funcionamento e necessidade desse atendimento, procurando sempre ajudar no que se é possível, pois, o AEE não é restrito apenas para os alunos matriculados na escola, mas, a todos da comunidade que precisarem. Por isso que é interessante que toda comunidade participe e saiba o essencial sobre o atendimento, para que, assim, possa divulgar o trabalho oferecido. (MENEZES, 2016, p. 7)

É importante deixar claro que a falta de valorização não se restringe aos professores de AEE, pois os docentes das disciplinas de Artes, Educação Física, Filosofia, Sociologia entre outras, geralmente sofrem com o mesmo problema, pois apesar de serem conhecimentos importantes para o desenvolvimento dos alunos, dentro de uma sociedade cada vez mais permeada por ideias neoliberais, eles acabam perdendo espaço dentro da escola por não serem considerados imprescindíveis e nem agregarem valor à 
formação de mão de obra dentro da lógica do mundo capitalista. Isso porque a simples existência de um tipo de atendimento que acaba por atuar, dentro da escola, com uma quantidade pequena de alunos, em comparação com as salas lotadas, choca-se frontalmente com as ideias neoliberais de diminuição dos gastos do Estado com educação e da lógica do rendimento e da eficiência.

\section{Considerações finais}

Retomamos aqui o objetivo do presente artigo, que foi conhecer a opinião dos professores de Atendimento Educacional Especializado acerca de como enxergam a valorização de seu trabalho pelos diversos indivíduos que permeiam o ambiente escolar.

De forma resumida, os achados indicam que os docentes de AEE participantes do estudo acreditam que quem mais valoriza o seu trabalho são os seus próprios alunos, seguidos dos familiares desses alunos, dos outros profissionais que por ventura trabalham na sala de recursos e do Coordenador(a) pedagógico(a) da escola onde ocorre o atendimento.

Entretanto, os mesmos professores creem que os outros alunos que frequentam as salas de aula regular e os seus respectivos professores, além do(a) Diretor(a) da escola, do(a) Secretário(a) de educação e de outros funcionários da escola, apenas valorizam em parte o seu trabalho.

Foi possível observar, portanto, no que diz respeito à realidade dos municípios da região do Piemonte da Diamantina/BA, que a valorização dos docentes que atuam com $\mathrm{AEE}$, apesar de ser reconhecida por alguns atores que a vivenciam cotidianamente, ainda é motivo de preocupação, principalmente nos sujeitos que atuam na gestão educacional.

Compreendendo que esse é um tema que não se esgota com este estudo, acreditamos ser importante que outros estudos com professores de AEE sobre o assunto sejam produzidos por pesquisadores de outras cidades e/ou de outros estados do Brasil. 


\section{Referências}

ABRÃO, Ruhena Kelber; DUARTE, Marisol Maiche. O papel da afetividade no processo ensino e aprendizagem da criança com deficiência. Revista UNIABEU, Belford Roxo, v.10, n. 24, p. 01-18, jan./abr. 2017.

BASTOS, Remo Moreira Brito. Sistema Educacional Cubano: fatores explicativos e reprodutibilidade em outras formações sociais. Cadernos de Pesquisa: pensamento educacional, Curitiba, v. 11, n. 27, p. 34-62, jan./abr. 2016.

BOUKOU, Jean Claude. Identites professionnelles des enseignant(e)s: analyse des situations et études comparatives entre le Congo-Brazzaville et le Congo-Kinshasa. 2017. 338 p. Thèse (Doctorat en Sociologie du travail) - Conservatoire National des Arts et Métiers, Paris, Paris.

BRASIL. Decreto ${ }^{\circ}$ 7.611/2011. Dispõe sobre a educação especial, o atendimento educacional especializado e dá outras providências. Brasília: Presidência da República, 2011.

BRASIL. Lei Nº 9.394, de 20 de dezembro de 1996. Estabelece as diretrizes e bases da educação nacional. Brasília: Presidência da República, 2011.

BRASIL. Constituição da República Federativa do Brasil. Brasília, DF: [s.n.], 1988.

CAYE, Ivone Trevisan; ULBRICHT, Leandra; NEVES, Eduardo Borba. Qualidade de vida no trabalho dos professores de matemática e português do ensino fundamental. Revista da Universidade Vale do Rio Verde, Três Corações, v. 12, n. 2, p. 974-989, ago./dez. 2014

FREITAS, Helena Costa Lopes de. Formação inicial e continuada: a prioridade ainda postergada. In: OLIVEIRA, Dalila Andrade; VIEIRA, Livia Maria Fraga (org.). Trabalho na educação básica: a condição docente em sete estados brasileiros. Belo Horizonte: Fino Traço, 2012. p. 468.

GALGÓCZI, Béla; GLASSNER, Vera. Comparative study of teacher's pay in Europe. Bussels: El/ETUCE, 2008.

GIL, Antônio Carlos. Como elaborar projetos de pesquisa. 5. ed. São Paulo: Atlas, 2010.

MAUCH, Carla; SANTANA, Wagner. Escola para todos: experiências de redes municipais na inclusão de alunos com deficiência, TEA, TGD e altas habilidades. Brasília: UNESCO, 2016. 100 p.

MENEZES, Rayssa Rafaela de Lima. Atendimento educacional especializado - AEE: necessidade e funcionamento no município de Apodi/RN. 2016. 26 p. Trabalho de conclusão de curso (Licenciatura em Pedagogia) - Universidade Federal do Rio Grande do Norte, Natal, 2016. 
MIRANDA, Theresinha Guimarães. A relação entre o professor da educação especial e da educação comum. Jorsen - Journal of research in special education needs, Wileyblackwell, v. 16, p. 98-105, 2016.

OLIVEIRA, Naira Maria da Silva. O professor do atendimento educacional especializado: atuação e representações sociais. 2015. 49 p. Trabalho de Conclusão de Curso (Especialização em Desenvolvimento Humano, Educação e Inclusão Escolar) Universidade de Brasília. Brasília, 2015.

OLIVEIRA, João Ferreira de; MAUÉS, Olgaíses Cabral. A formação docente no Brasil: cenário de mudanças políticas e processos em debate. In: OLIVEIRA, Dalila Andrade; VIEIRA, Lívia Fraga. Trabalho na educação básica: a condição docente em sete estados brasileiros. Belo Horizonte: Fino Traço Editora Ltda., 2012.

OLIVEIRA, Lourival José de; PIRES, Ana Paula Vicente. Da precarização do trabalho docente no Brasil e o processo de reestruturação produtiva. Revista do direito público, Londrina, v.9, n.1, p.73-100, jan./abr. 2014.

SILVA, Fernanda Aparecida Oliveira. As intercorrências da precarização do trabalho docente na saúde de professores do ensino médio. 2017. 68 f. Trabalho de conclusão de curso (Licenciatura em Pedagogia) - Universidade Federal de Uberlândia, 2017.

SILVEIRA, Luzia Aparecida. Política pública e educação inclusiva: o lugar das salas de recursos multifuncionais - estudo de caso sobre o município de Candelária. 2012. 50 p. Trabalho de conclusão de curso (Especialização em Gestão Pública) - Universidade Federal do Rio Grande do Sul, São Sepé, 2012.

VENTURINI, Angela Maria; SENNA, Manoella. Os limites e as possibilidades das Salas de Recursos Multifuncionais: as vozes dos professores. In: VI CONGRESSO BRASILEIRO DE EDUCAÇÃO ESPECIAL, 6., 2014, São Carlos. Anais [...]. São Carlos: Galoá, 2014. v. 01. p. $29504-29517$.

TOH, Alain. Précarisation de la profession enseignante au primaire en Côte d'Ivoire.

Formation et profession, Montréal, v. 25, n. 2, p. 20-34, 2017.

TOSTES, Maiza Vaz et al. Sofrimento mental de professores do ensino público. Saúde debate, Rio de Janeiro, v. 42, n. 116, p. 87-99, jan. 2018.

TOURIGNY, Mylène Auclair. Besoins de soutien des enseignants du primaire québécois: analyse de leurs perceptions en vue de proposer des pistes d'amélioration de leur contexte de pratique professionnelle. 2017. 222 p. Thèse (Doctorat en Psychologie) Université de Sherbrooke, Quebec, 2017. 
Recebido em: $16 / 04 / 2020$

Revisões requeridas em: 12/12/2020

Aprovado em: 04/05/2021

Universidade do Estado de Santa Catarina - UDESC Programa de Pós-Graduação em Educação - PPGE

Revista Linhas

Volume 22 - Número 49 - Ano 2021

revistalinhas@gmail.com 